\title{
Separation of Fischer-Tropsch Wax from Catalyst by Supercritical Extraction
}

Report Type: QUARTERLY $\mid$ Reporting Period Start Date: 04/01/1998 End Date: 06/30/1998 Principal Author(s): Patrick C. Joyce and Mark C. Thies 


\section{Disclaimer}

This report was prepared as an account of work sponsored by an agency of the United States Government. Neither the United States Government nor any agency thereof, nor any of their employees, makes any warranty, express or implied, or assumes any legal liability or responsibility for the accuracy, completeness, or usefulness of any information, apparatus, product, or process disclosed, or represents that its use would not infringe privately owned rights. Reference herein to any specific commercial product, process, or service by trade name, trademark, manufacturer, or otherwise does not necessarily constitute or imply its endorsement, recommendation, or favoring by the United States Government or any agency thereof. The views and opinions of authors expressed herein do not necessarily state or reflect those of the United States Government or any agency thereof. 


\section{Executive Summary}

An investigation of the ability of the Peng-Robinson (P-R) equation to correlate the phase behavior of the systems measured in this project, which consist of mixtures of hexane with long-chain alkanes, has been initiated. To allow an unbiased comparison with modern equations of state such as SAFT, pure component parameters for P-R were regressed from pure component vapor pressure and liquid density data. Using these regressed parameters, our measured binary phase equilibrium data for the hexane/hexadecane and hexane/tetracosane systems were correlated. For the hexane/hexadecane system, a good fit was obtained using a small, nearly constant interaction parameter. For the hexane/tetracosane binary, significant improvement in data correlation was obtained compared to the method of using experimental critical properties. However, the binary interaction parameters were still found to vary with temperature. Similar work is currently being performed on other systems previously measured at Clemson; a summary of this work will be presented in the next quarterly report.

VLE has already been measured for the hexane/hexatriacontane $\left(n \mathrm{C}_{36} \mathrm{H}_{74}\right)$ system at 250,300 and $350{ }^{\circ} \mathrm{C}$. Experiments at $200{ }^{\circ} \mathrm{C}$ are currently underway, but difficulties are being experienced in the measurement of the very low wax compositions that exist in the vapor phase. An impurity of the same level (i.e., ppm) as the wax has been detected in the vapor-phase samples. We have yet to determine the source of this impurity. Liquidphase compositions have been successfully measured and are believed to be accurate to better than $\pm 3 \%$. 


\section{Technical Objectives}

The objective of this research project is to evaluate the potential of supercritical fluid (SCF) extraction for the recovery and fractionation of the wax product from the slurry bubble column $(\mathrm{SBC})$ reactor of the Fischer-Tropsch $(\mathrm{F}-\mathrm{T})$ process. The wax, comprised mostly of branched and linear alkanes with a broad molecular weight distribution up to $\mathrm{C}_{100}$, will be extracted with a hydrocarbon solvent that has a critical temperature near the operating temperature of the SBC reactor, i.e., $200-300{ }^{\circ} \mathrm{C}$. Initial work is being performed using $n$-hexane as the solvent.

The success of the project depends on two factors. First, the supercritical solvent must be able to dissolve the F-T wax; furthermore, this must be accomplished at conditions that do not entrain the solid catalyst. Second, the extraction must be controlled so as not to favor the removal of the low molecular weight wax compounds. That is, a constant carbon-number distribution in the wax slurry must be maintained at steady-state column operation. Three major tasks are being undertaken to evaluate our proposed SCF extraction process. Task 1: Equilibrium solubility measurements for model F-T wax components in supercritical fluids at conditions representative of those in a SBC reactor. Task 2: Thermodynamic modeling of the measured VLE data for extending our results to real wax systems. Task 3: Process design studies of our proposed process. Additional details of the task structure are given below.

\section{Task 1: Equilibrium Solubility Measurements}

a. apparatus modification and construction.

b. experimental measurements of selected model systems.

c. design and construction of new apparatus for measuring VLE of $\mathrm{C}_{36}+$ alkanes with hexane.

Task 2: Thermodynamic Modeling

a. modeling VLE data using cubic equations of state.

b. examination of theoretically based models, including the SAFT equation.

Task 3: Process Design Studies

a. process configuration studies using the ASPEN PLUS simulation package. 


\section{Detailed Description of Technical Progress}

\section{Task 1a. Apparatus Modification and Construction}

This task has been completed.

\section{$\underline{\text { Task 1b. Experimental Measurements for Model Wax Components }}$}

VLE measurements for the hexane/hexatriacontane system at $197.2^{\circ} \mathrm{C}$ were performed. The measured liquid-phase compositions are shown in Table I and were always reproducible to better than $\pm 3 \%$ in terms of the minor component. However, difficulties were encountered with the vapor phase, that is, a contaminant was found in all vapor-phase samples. Because the contaminant is of a similar concentration to that of the solute in the vapor phase (i.e., at the ppm level), it interferes with the accurate determination of vapor-phase compositions. The source of the contaminant has yet to be determined. Essentially no decomposition was observed at the higher temperatures, so none was expected at $200{ }^{\circ} \mathrm{C}$. The solvent hexane, the apparatus lines, and the $\mathrm{GC}$ vials have thus far been eliminated as possible contaminant sources. At the moment, we are determining whether a coating on the sample vial caps may be the culprit.

Table I. Liquid-phase compositions for the hexane/hexatriacontane system at $197.2{ }^{\circ} \mathrm{C}$.

\begin{tabular}{cccc}
\hline $\mathrm{P}($ bar $)$ & $\mathrm{x}\left(\right.$ mole fraction $\left.\mathrm{C}_{36}\right)$ & $\mathrm{P}($ bar $)$ & $\mathrm{x}\left(\right.$ mole fraction $\left.\mathrm{C}_{36}\right)$ \\
\hline 7.91 & 0.387 & 14.80 & 0.0974 \\
9.63 & 0.294 & 16.53 & 0.0366 \\
11.36 & 0.231 & 16.87 & 0.0249 \\
13.08 & 0.161 & & \\
\hline
\end{tabular}

\section{Task 1c. Design and Construction of New Apparatus}

Construction of a magnetic pump suitable for elevated temperatures was planned, but we have yet to receive the necessary magnets from the supplier.

\section{Task 2a. Modeling VLE Data Using Cubic Equations of State}

Previous results have shown that Peng-Robinson (P-R), as conventionally used, is not capable of correlating phase compositions for hexane/large alkane $\left(\mathrm{C}_{24+}\right)$ systems. The 
problem may arise from how the pure component parameters for the long-chain alkanes are determined (normally, they are obtained from measured critical properties and vapor pressures). One indication of the problem with $\mathrm{P}-\mathrm{R}$ is the fact that the predicted liquid densities decrease with increasing molecular weight, contrary to experimental observation. An obvious point, but one that is too frequently overlooked by researchers, is that an equation of state first must be capable of predicting pure component properties before one attempts to use if to fit mixture data.

As a first step in improving both the correlative and predictive ability of P-R, we have used vapor pressure and liquid density data to determine the values of $\mathrm{T}_{c}, \mathrm{P}_{c}$, and $\kappa$. A downhill simplex method was used to simultaneously regress the three parameters so as to obtain the best fit to the input pure component data for each component. It should be noted that this method is identical to that used to obtain pure component parameters for modern equations of state such as PHCT and SAFT. Using the regressed critical properties and $\kappa$, good fits (i.e., within $\pm 3 \%$ ) to the input data were obtained. The P-R parameters are calculated from critical properties using the following equations, where $T_{c}$ is the critical temperature, $\mathrm{P}_{\mathrm{c}}$ is the critical pressure, and $\mathrm{R}$ is the gas constant:

$$
\begin{aligned}
a_{c} & =\frac{0.45724 R^{2} T_{c}^{2}}{P_{c}} \\
b & =\frac{0.07780 R T_{c}}{P_{c}}
\end{aligned}
$$

Both the experimental (exp) and regressed (reg) properties are shown in Table II below. The regressed parameters are generally well-behaved, but the $\mathrm{T}_{\mathrm{c}}$ for hexatriacontane is somewhat questionable. It is probably not a coincidence that the data for this component are also the least certain, with only one data source available. 
Table II. Comparison of experimental and regressed critical properties.

\begin{tabular}{ccccccc}
\hline Component & $\mathrm{T}_{\mathrm{c}}(\exp )$ & $\mathrm{T}_{\mathrm{c}}(\mathrm{reg})$ & $\mathrm{P}_{\mathrm{c}}(\exp )$ & $\mathrm{P}_{\mathrm{c}}(\mathrm{reg})$ & $\kappa(\exp )$ & $\kappa(\mathrm{reg})$ \\
\hline Hexane & 507.5 & 510.0 & 30.25 & 31.11 & 0.8116 & 0.8315 \\
Hexadecane & 722.0 & 729.8 & 14.1 & 16.33 & 1.3704 & 1.3750 \\
Tetracosane & 800.0 & 829.8 & 8.7 & 12.89 & 1.7825 & 1.6736 \\
Octacosane & 824.0 & 861.1 & 7.44 & 11.38 & 1.9993 & 1.8201 \\
Hexatriacontane & 872.0 & 858.7 & 4.72 & 8.88 & 2.2511 & 2.6200 \\
\hline
\end{tabular}

Figures 1 and 2 depict the variation of the $\mathrm{a}_{\mathrm{c}}$ and $\mathrm{b}$ terms (determined from both experimental and regressed critical properties) versus carbon chain length in alkanes. As can be seen in both figures, at low molecular weights the two terms are nearly the same. However, as the chain length increases, the difference between the parameters becomes large. It should be noted that both the $\mathrm{a}_{\mathrm{c}}$ and $\mathrm{b}$ terms are linear over the range of molecular weights examined. If the reasons behind this behavior can be understood, it may be possible to extrapolate (or at the very least interpolate) parameters for the P-R equation when little pure component information is available.

With the improved fit of P-R to pure component properties, the next test was to determine its ability to fit binary VLE data. Initial tests were performed on two systems, hexane/hexadecane and hexane/tetracosane. Table III shows the deviation between calculated and experimentally measured liquid- and vapor-phase compositions for the hexane/hexadecane binary. As can be seen, by using a small, nearly constant interaction parameter it is possible to get a good fit to the experimental data. (However, it should be pointed out that this was also true when the pure component parameters were experimentally determined.) The table also indicates that using the regressed critical properties actually improved the fit of P-R to the experimental data, but with one caveat: Figures 3 and 4 also indicate that there has been some deterioration in the prediction of the mixture critical points, a fact that the regression numbers shown in Table III do not take into account.

For the hexane/tetracosane system, significant improvements in the fit to the liquid-phase compositions were obtained at the higher temperatures, and vapor-phase fits were generally good (see Figures 5 and 6). However, no improvement in the fit at the critical points is observed. In addition, the optimized binary interaction parameters are 
relatively large and vary strongly with temperature, although to a lesser extent than by fitting the data by conventional means. Additional work with other binary systems measured at Clemson is required before conclusions can be drawn as to the ability of P-R to correlate and predict phase compositions for systems of asymmetric alkanes using standard (i.e., van der Waals one fluid) mixing rules.

Table III. Optimized binary interaction parameters for the Peng-Robinson equation (with regressed parameters) and deviations between experimental and calculated results for the hexane/hexadecane system.

\begin{tabular}{cccc}
\hline Temperature $\left({ }^{\circ} \mathrm{C}\right)$ & Optimized $\mathrm{k}_{\mathrm{ij}}$ & $\mathrm{x} \mathrm{error}^{\mathrm{a}}(\%)$ & $\mathrm{y}$ error $(\%)$ \\
\hline 199.2 & -0.01 & 6.9 & 1.9 \\
251.3 & 0.00 & 7.7 & 2.2 \\
299.4 & -0.01 & 2.1 & 3.3 \\
349.8 & -0.01 & 1.1 & 2.2 \\
${ }^{\mathrm{a}} \mathrm{AAPD}=\sum_{\mathrm{i}}\left|\frac{\left(\mathrm{x}_{\mathrm{i}}\left[\operatorname{exp]}-\mathrm{x}_{\mathrm{i}}[\mathrm{calc}]\right)\right.}{\mathrm{x}_{\mathrm{i}}[\mathrm{exp}]}\right| \times 100 \%$ & &
\end{tabular}

Table IV. Optimized binary interaction parameters for the Peng-Robinson equation (with regressed parameters) and deviations between experimental and calculated results for the hexane/tetracosane system.

\begin{tabular}{cccc}
\hline Temperature $\left({ }^{\circ} \mathrm{C}\right)$ & Optimized $\mathrm{k}_{\mathrm{ij}}$ & $\mathrm{x} \mathrm{error}^{\mathrm{a}}(\%)$ & $\mathrm{y}$ error $(\%)$ \\
\hline 199.8 & 0.00 & 14.2 & 6.2 \\
251.1 & -0.02 & 13.2 & 6.4 \\
300.3 & -0.07 & 4.3 & 8.4 \\
349.8 & -0.09 & 3.7 & 4.0 \\
${ }^{\mathrm{a}} \mathrm{AAPD}=\sum_{\mathrm{i}}\left|\frac{\left(\mathrm{x}_{\mathrm{i}}\left[\operatorname{exp]}-\mathrm{x}_{\mathrm{i}}[\mathrm{calc}]\right)\right.}{\mathrm{x}_{\mathrm{i}}[\exp ]}\right| \times 100 \%$ & &
\end{tabular}

Task 2b. Examination of Theoretically Based Equations of State

No effort planned this quarter.

Task 3a. Process Configuration Studies Using the ASPEN PLUS Simulation Package

No effort planned for this quarter. 


\section{Plans for Next Quarter}

During the next quarter, research will focus on further examining the ability of Peng-Robinson to predict phase behavior in systems of interest. Several different mixing rules will be examined to determine their predictive ability. The magnetic pump for incorporation in the new apparatus will be assembled and tested. Finally, a selected binary system may be measured to test the predictive ability of any models that appear promising. 


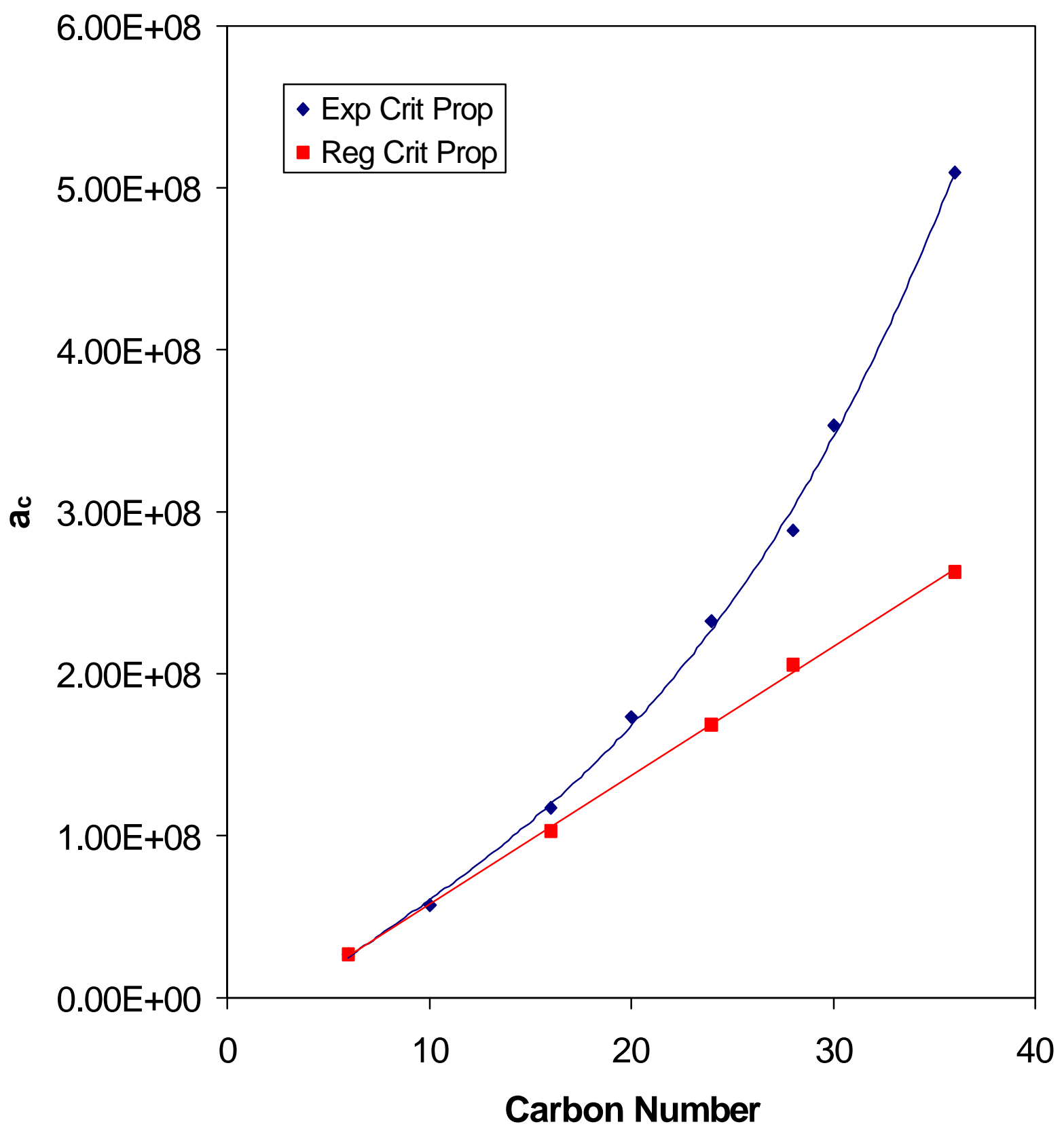

Figure 1. Comparison of the Peng-Robinson parameter, $a_{c}$, using experimental and regressed critical properties (line is a best fit to points). 


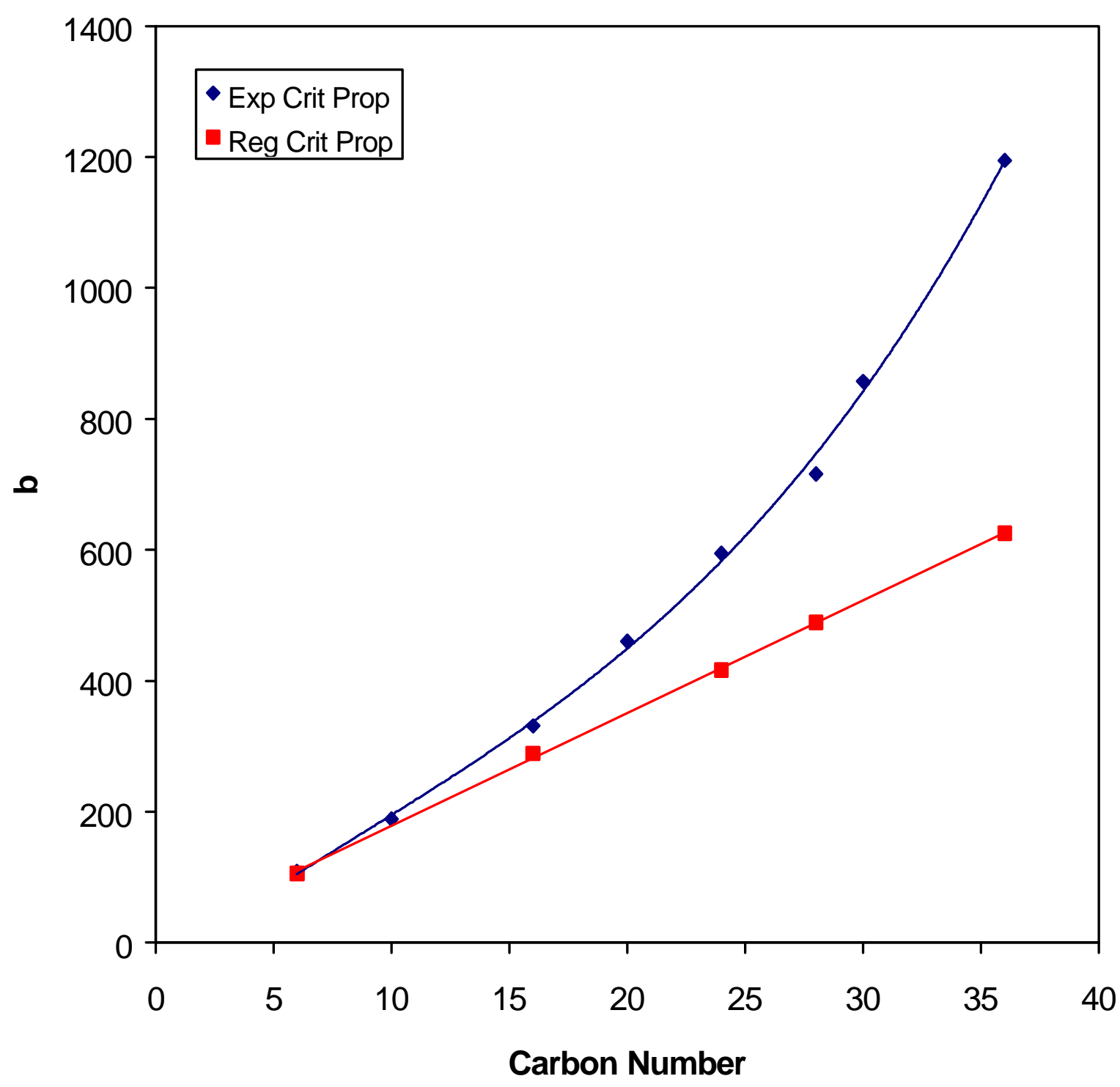

Figure 2. Comparison of the Peng-Robinson parameter, $b$, using experimental and regressed critical properties (line is a best fit to points). 


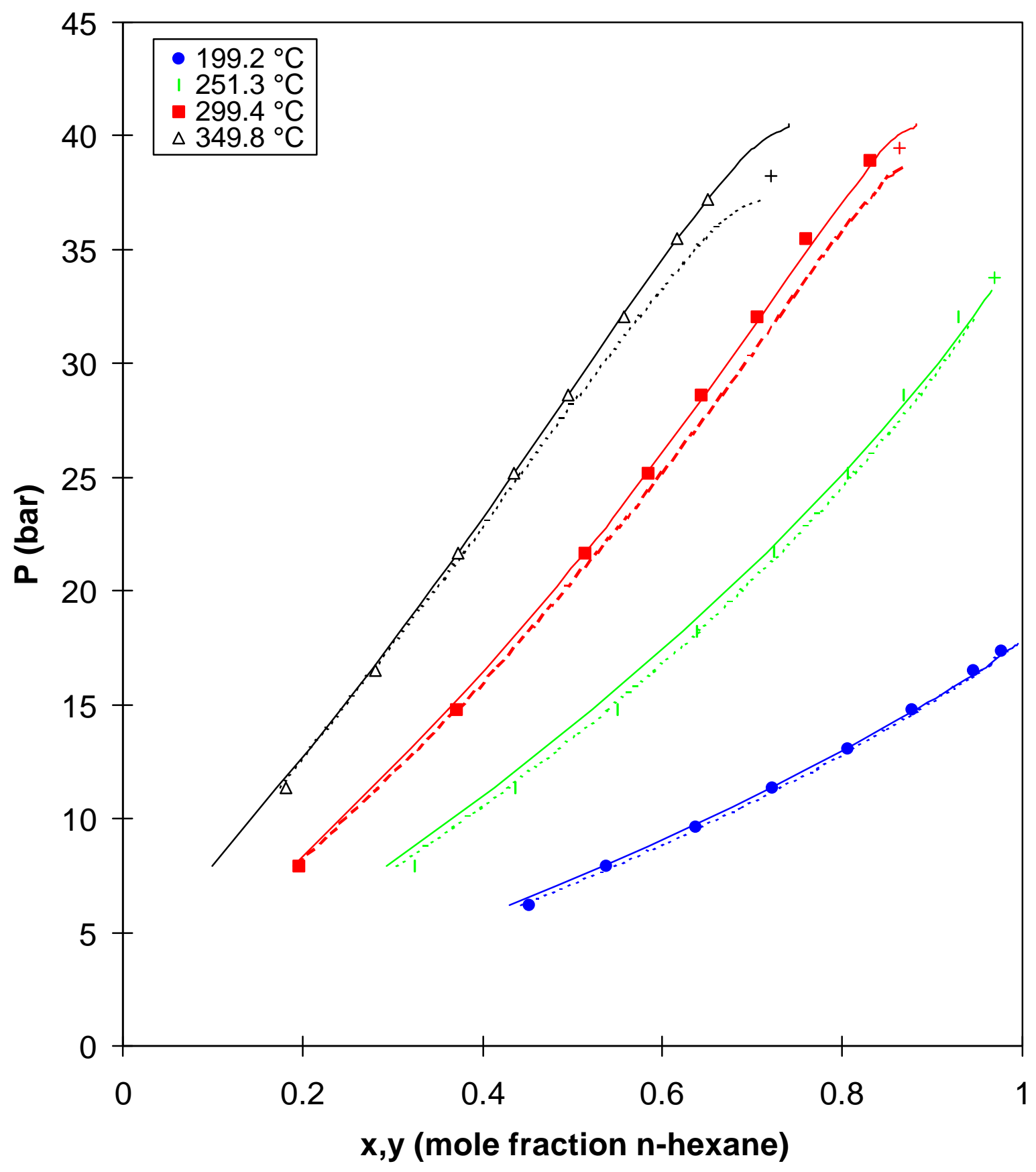

Figure 3. Comparison of Peng-Robinson with experimental data for the liquid-phase compositions of the hexane/hexadecane system (the solid line is P-R with regressed critical properties and the dashed line is $\mathrm{P}-\mathrm{R}$ with experimental critical properties). 


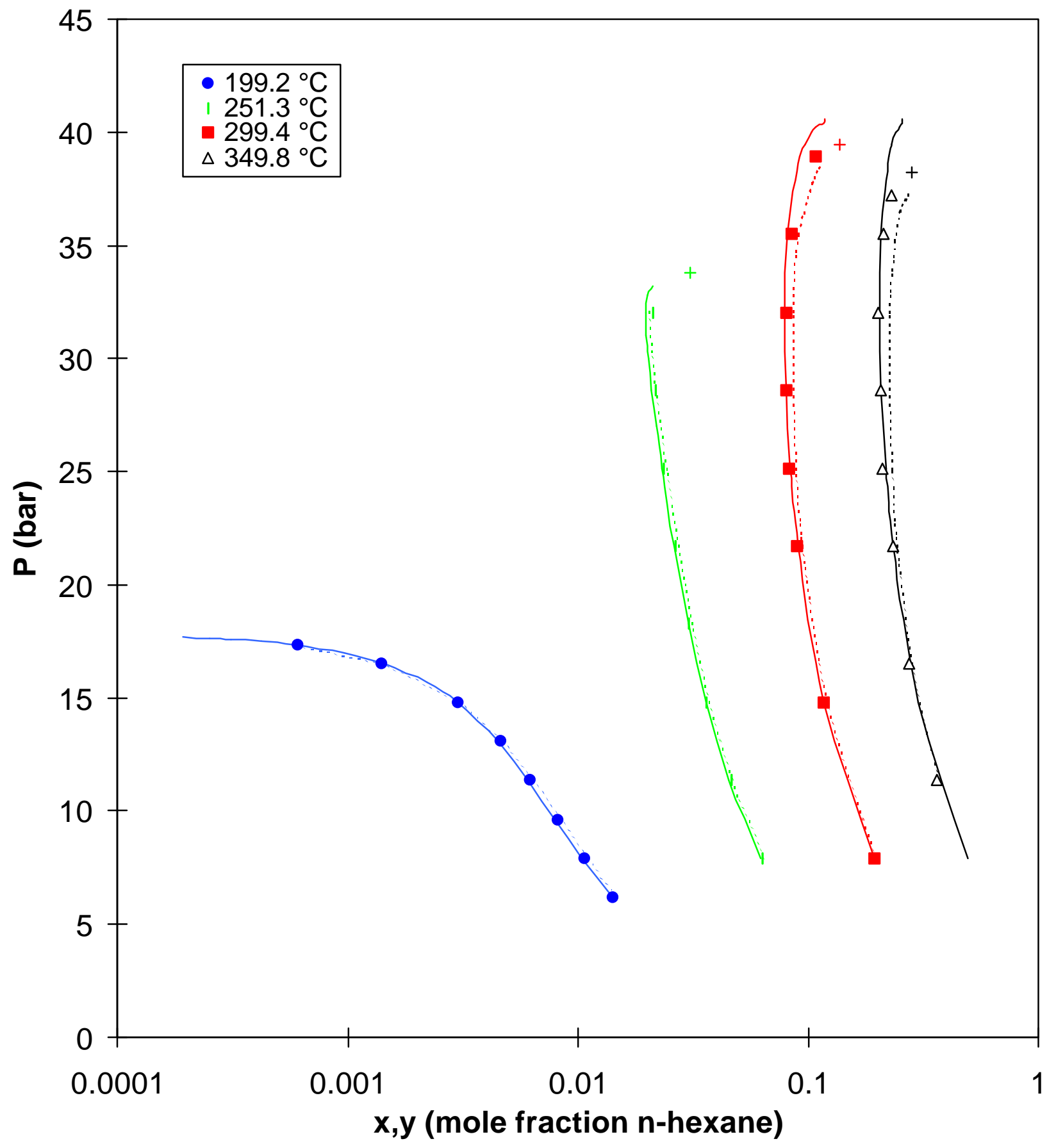

Figure 4. Comparison of Peng-Robinson with experimental data for the vapor-phase compositions of the hexane/hexadecane system (the solid line is P-R with regressed critical properties and the dashed line is $\mathrm{P}-\mathrm{R}$ with experimental critical properties). 


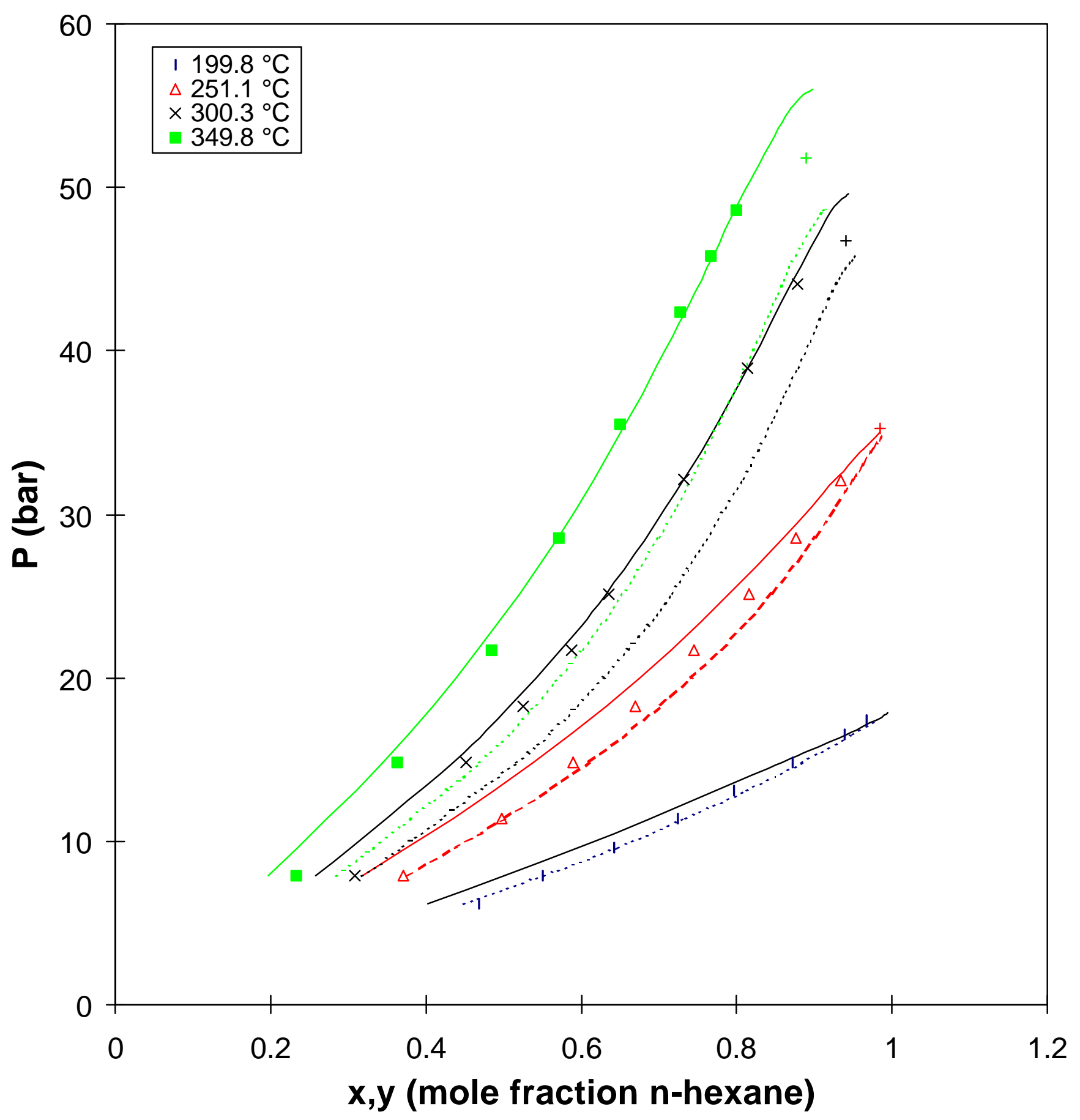

Figure 5. Comparison of Peng-Robinson with experimental data for the liquid-phase compositions of the hexane/tetracosane system (the solid line is P-R with regressed critical properties and the dashed line is $\mathrm{P}-\mathrm{R}$ with experimental critical properties). 


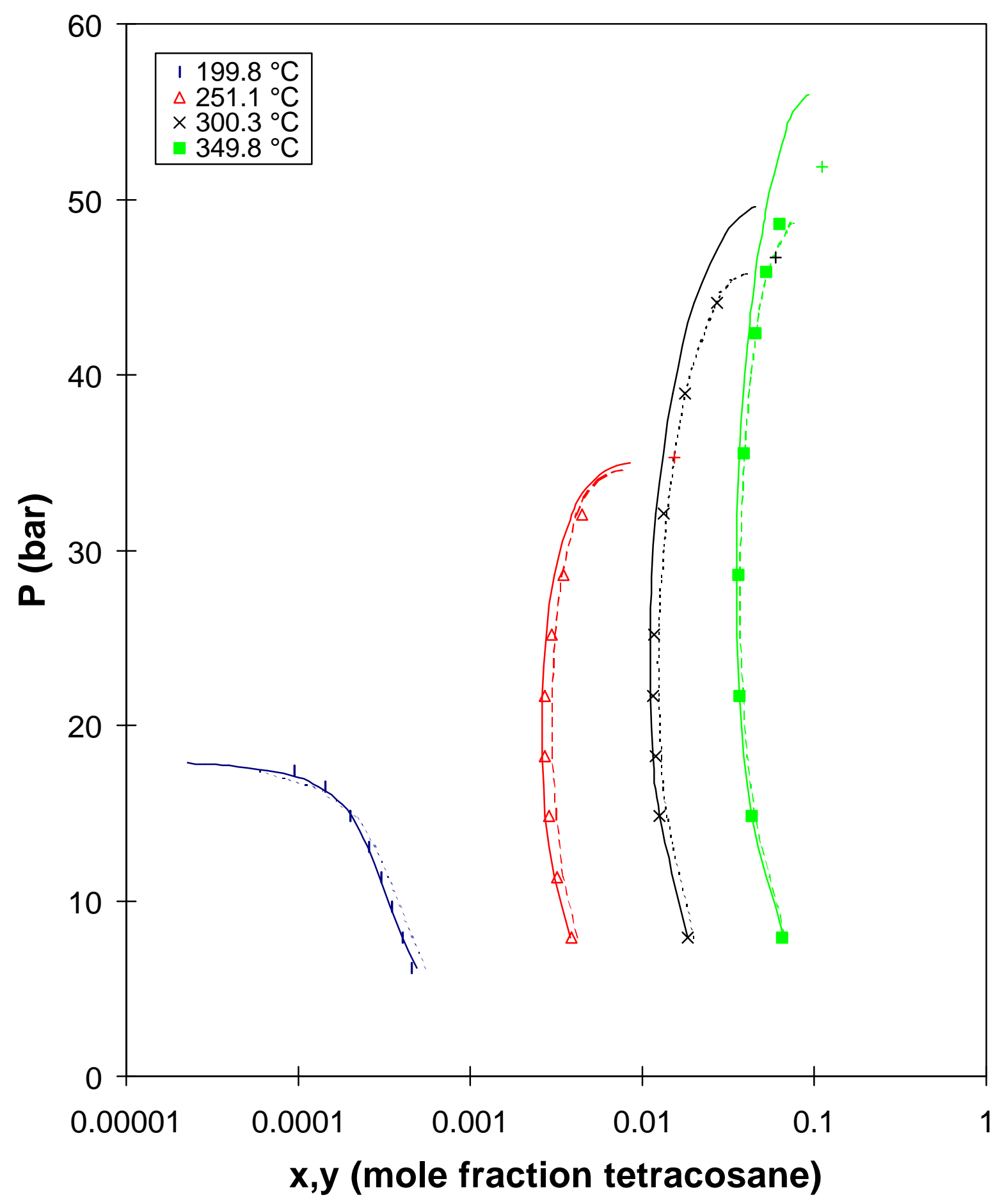

Figure 6. Comparison of Peng-Robinson with experimental data for the vapor-phase compositions of the hexane/tetracosane system (the solid line is P-R with regressed critical properties and the dashed line is $\mathrm{P}-\mathrm{R}$ with experimental critical properties). 